\title{
Mesenchymal stem cells as a reference cell for HLA-typing
}

Roohollah Mirzaee Khalilabadi ${ }^{1}$, Fatemeh Yari $^{1 *}$, Naser Amirizadeh ${ }^{1}$, Mahin Nikougoftar ${ }^{1}$, Arezoo Oodi ${ }^{1}$

1. Blood Transfusion Research Center, High Institute for Research and Education in Transfusion Medicine, Tehran, Iran

*Corresponding author: Tel: +98 2182052238 Fax: +98 2188601555

Address: IBTO bldg., Hemmat Way, Next to the Milad Tower, Tehran, Iran, P.O. Box: 14665-1157

E-mail: f.yari@ibto.ir

Received; 2016/01/2 revised; 2016/05/9 accepted; 2016/07/1

\section{Abstract}

Introduction: Recognition of human leukocyte antigens (HLA) is of importance for hematopoietic stem cell transplantation. Any HLA-mismatches between the donor and recipient can cause graft rejection or other complications. In HLA-typing experiments, usage of HLA-known reference cells accompany with HLA-unknown samples is obligatory. Some international centers represent these cells with high expenses. On the other hand, transferring of these cells is problematic and in some instances is not practical. In this study, we introduced umbilical cord-derived mesenchymal stem cells (MSCs) as reference cells for HLA genotyping. These cells are national and can be prepared locally.

Materials and methods: We isolated MSCs from three umbilical cord and after their growth and proliferation, these cells were characterized by flow cytometry technique using antibodies to CD29, CD34, CD44, CD45, CD73, CD90 and CD105. HLA-typing was then carried out by PCR-SSP kits for HLA-A, -B and -DRB allele's identification.

Results: Isolated MSCs were positive for MSCs markers; CD29, CD44, CD73, CD90, and CD105 and negative for hematopoietic stem cell markers; CD34 and CD45. HLA alleles were determined. One of the samples was homologous for HLA alleles and the others were heterologous.

Conclusion: We can develop a reference panel for HLA-typing by obtaining MSCs from available sources like umbilical cord.

Keywords: HLA-typing, Mesenchymal stem cells, Reference panel, Umbilical cord

\section{Introduction}

Similarities in human leukocyte antigens (HLA) are of important requirements for bone marrow transplantation (1-4). Mismatching between the recipient and donor's HLA antigens can cause transplant rejection and graft versus host disease (GVHD) (2-6). Both serological and molecular techniques are used to find the best HLA match subjects $(3,4,7)$. Molecular techniques are more precise and reliable than serological techniques (7-10). Different types of molecular techniques are used for HLA-typing (1, 3, 4). Control reference cells or DNAs with known HLA alleles are used in these techniques. (11-
14). There are some centers in the world that provide these control samples such as IHWG. Different types of cells are used to provide HLA panels, but many of these cells need special conditions for their growth and proliferation $(3,15,16)$. On the other hand, any country and nation have their specific alleles so it is better to use the control samples with their own alleles.

In this study we introduced mesenchymal stem cells (MSCs) as control cells in HLAtyping. MSCs are one type of stem cells that are existed in different tissues such as, umbilical cord, wharton's jelly, cord blood, bone marrow, dental pulp and adipose 
tissues (17-21) .They have stem cells properties such as self-renewality and differentiation capacity(17, 20-24).Their morphology under microscope is spindleshape and adherent $(17,20)$. They are positive for CD29, CD44, CD73, CD90, CD105 and CD166 (18, 20, 21, 22, 25, 26) and negative for hematopoietic stem cell markers CD34 and CD45 (17, 20, 21, 25,). In this study we used MSCs as control cells in HLA-typing because:

1) These cells don't need unique conditions for their growth and proliferation.

2) These cells can be isolated from different sources such as, umbilical cord, Wharton's jelly, cord blood, bone marrow, and adipose tissue so they are accessible.

\section{Materials and methods}

Isolation of MSCs: Three umbilical cords were obtained from Iranian cord blood cell bank in Iran Blood Transfusion Organization (IBTO). Umbilical cord specimens were cut in to very small pieces in sterile conditions and washed with PBS. Tissue pieces were put in $1 \mathrm{mg} / \mathrm{ml}$ collagenase type IV solution (GIBCO, USA) and incubated in $37^{\circ} \mathrm{C}$ for $3-4 \mathrm{~h}$. Then the solution was filtered to isolate cell suspension from debris. Cell suspension was washed with PBS and centrifuged. The supernatant was removed and cell pellet was dissolved in DMEM medium supplemented with $10 \%$ FBS, $1 \%$ penicillin and streptomycin (prepared from a stock solution of $100 \mathrm{X}$ concentration contained $10,000 \mathrm{IU} / \mathrm{mL}$ penicillin and 10,000 ug/mL of streptomycin) and $1 \% \quad \mathrm{~L}$-gln and incubated in $37 \mathrm{C} \circ$ and $5 \% \mathrm{CO} 2$ incubator.

Characterization of MSCs: The morphology of MSCs was observed under inverted microscope. Immunophenotyping of MSCs was carried out with flow cytometry technique.

Eight antibodies were used for the detection of CD markers of MSCs surface: anti CD29-FITC, anti CD34-PE, anti CD44FITC, anti CD45-FITC, anti CD73-PE, anti
CD90-PE and anti CD105-FITC (all from BD Biosciences, USA).

HLA genotyping: DNA was extracted from MSCs with viability more than 95 percent. Salting out method was used for the extraction of DNA. The concentration and purity of extracted DNA was determined by NanoDrop spectrophotometer (WPA, UK).

HLA genotyping and allele identification was carried out using PCR-SSP method. ABDR HLA typing kit (Olerup SSP HLA typing kit, Sweden) was used for HLA genotyping. PCR was carried out with 30 ng of the genomic DNA in a total volume of $10 \mu 1$ of the reaction mixture. Addition of DNA, master mix and Taq DNA polymerase was accomplished as the manufacturer's instructions. The PCRcycling conditions were as follows: initial denaturation at $94^{\circ} \mathrm{C}$ for $2 \mathrm{~min}$, followed by 10 cycles of $94^{\circ} \mathrm{C}$ for $10 \mathrm{~s}$ and $65^{\circ} \mathrm{C}$ for 60 $\mathrm{s}$ and another 20 cycles of $94^{\circ} \mathrm{C}$ for $10 \mathrm{~s}$, $61^{\circ} \mathrm{C}$ for $50 \mathrm{~s}$ and $72^{\circ} \mathrm{C}$ for 30 s.PCR products were analyzed on a $1.5 \%$ agarose gel with GelRed ${ }^{\mathrm{TM}}$ (Olerup SSP HLA typing kit, Sweden). DNAs with specified alleles were used to control HLA typing results.

\section{Results}

Characterization of the isolated cells: An image for the cultured isolated cells was shown in Fig. 1. These cells were spindleshape and adherent. On the other hand, flow cytometry technique demonstrated that the surface markers of isolated cells were related to MSCs. The isolated cells were positive for MSC markers including CD29, CD44, CD73, CD90, and CD105 and negative for hematopoietic stem cell markers; CD34 and CD45 (Fig.2). This experiment confirmed the MSCs characterize for the adherent isolated cells. HLA-genotyping results: Concentrations of extracted DNA from three umbilical cordderived MSCs (UC-MSC 1, UC-MSC 2, and UC-MSC 3) were $48 \mu \mathrm{g} / \mathrm{ml}, 75 \mu \mathrm{g} / \mathrm{ml}$ and $57 \mu \mathrm{g} / \mathrm{ml}$, respectively. The purity of extracted DNA was determined using the 
ratio of OD260 to OD280 and were in an acceptable range; 1.72, 1.97 and 1.86. After PCR amplification, for identifying the HLA alleles, electrophoresis of PCR products was accomplished on a $1.5 \%$ agarose gel (Fig 3 and table 1). Each typing plate included 96 wells: 24 for HLA-A, 48 for HLA-B, 23 for HLA-DRB and 1 for negative control. The interpretation of results was accomplished according to the worksheets represented by the manufacture.

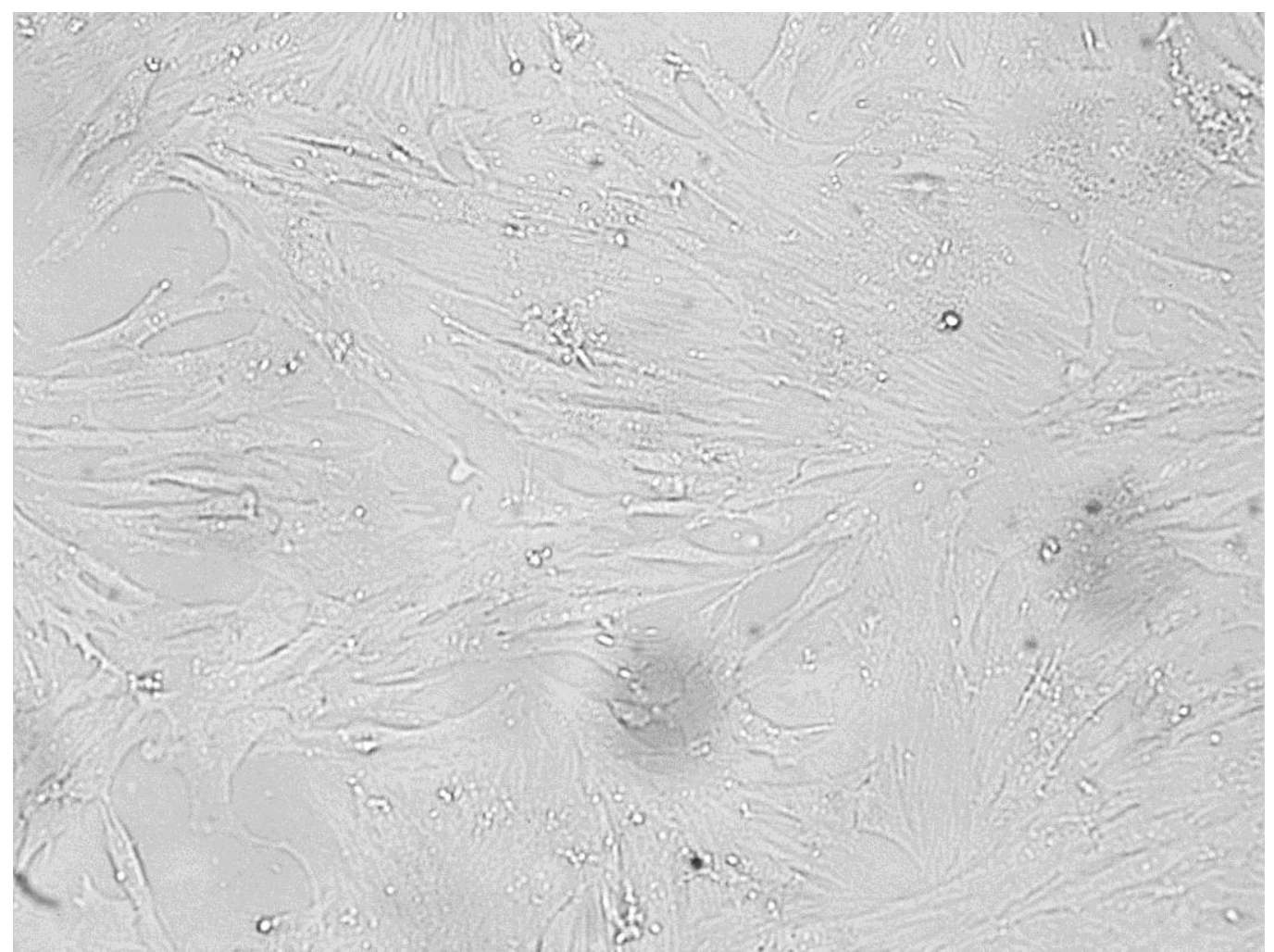

Figure 1. The isolated cells (MSCs) were observed under inverted microscope and were spindle-shape and adherent $(100 \mathrm{x})$.

Table 1. HLA Alleles in the studied umbilical cord MSCs. As it was shown, UC-MSC 1 was homologous for HLA Alleles and two others were heterologous.

\begin{tabular}{lccc}
\hline & \multicolumn{3}{c}{ Identified HLA alleles } \\
\cline { 2 - 4 } MSCs & HLA-A & HLA-B & HLA-DR \\
\hline UC-MSC 1 & $\mathrm{A} * 24$ & $\mathrm{~B} * 39$ & DRB $1 * 14 /$ DRB3* \\
UC-MSC 2 & $\mathrm{A} * 03, \mathrm{~A} * 24$ & $\mathrm{~B} * 35, \mathrm{~B} * 18$ & DRB $1 * 01, \mathrm{DRB} 1 * 11 / \mathrm{DRB} 3 *$ \\
UC-MSC 3 & $\mathrm{A} * 01, \mathrm{~A} * 32$ & $\mathrm{~B} * 44, \mathrm{~B} * 41$ & $\mathrm{DRB} 1 * 10, \mathrm{DRB} 1 * 13 / \mathrm{DRB} 3 *$ \\
\hline
\end{tabular}

HLA: human leukocyte antigen, MSCs: Mesenchymal stem cells, UC-MSC: Umbilical cord- mesenchymal stem cell. 

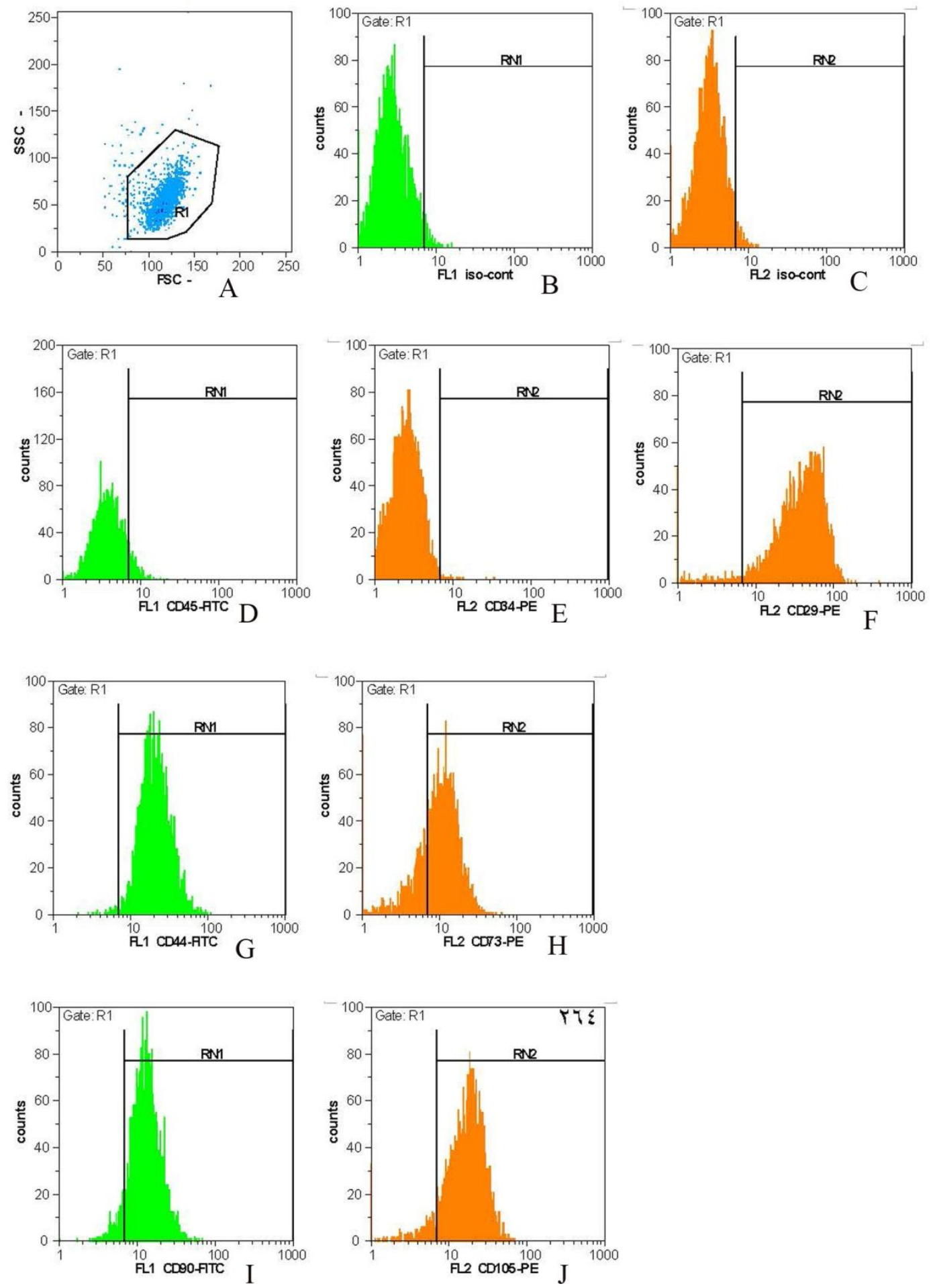

Figure 2. Flow cytometry plots. Characterization of isolated cells (A) gating of the cells. (B and C) isotype control. Immunophenotyping results showed that the isolated cells were negative for CD45 and CD34 (D and E, respectively) and positive for CD29, CD44, CD73, CD90, and CD105 (F-G, respectively). These characters were correlated with MSCs. 

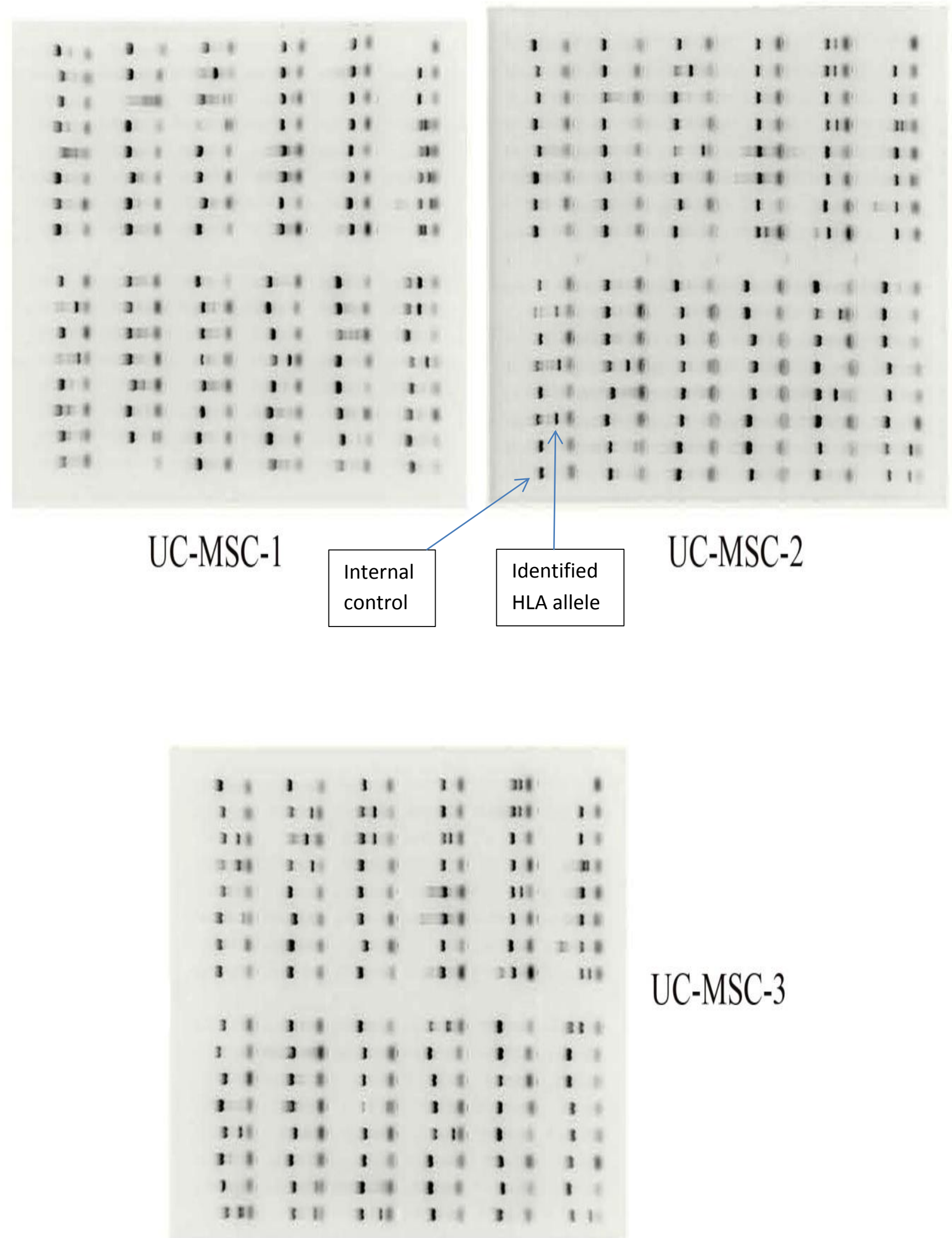

UC-MSC-3

Figure 3. HLA-genotyping results using PCR-SSP kits for three umbilical cord MSCs after electrophoresis. Each 96 reaction plate could determine the alleles of HLA-A, HLA-B and HLA-DRB for each sample. 


\section{Discussion}

HLA typing is essential for stem cell transplantation (SCT) because HLA compatibility between donor and recipient is important $(1,4)$. Otherwise, the graft is rejected or GVHD is occurred $(2,3)$. On the other hand, in HLA-typing, a suitable HLAknown control is necessary to be sure about the accuracy of HLA results (16). In this study, HLA typing was accomplished on MSCs derived from different tissues using PCR-SSP method. Since these cells were accessible and their growth and proliferation accomplished easily without need to unique medium so they could be used for preparing a reference panel for HLA genotyping. Different centers and companies such as IHWG, EBRCC-cell Culture laboratory and National Cancer Institute's Developmental Therapeutics Program (NCI-60) represented various cell lines or their related DNA and offered them as reference panel for different purposes like HLA genotyping $(16,27,28)$.

Michael Witti developed high-resolution next-generation sequencing (NGS)-based HLA-typing for cell lines from IHWG and EBRCC-cell as reference set to demonstrate the potential of NGS in HLA-typing. They used some random to fill out reference panel (29).

Hemmatpour used B lymphocyte cell lines as HLA-known controls in DNA-based HLA typing. (30).

NCI-60 cell lines, first, were used as screening tools to develop anti-cancer drugs, in early 90,s (31). But in 2005 Sharon Adams, performed a highresolution sequence-based HLA typing

\section{References}

1. Mahdi BM. A glow of HLA typing in organ transplantation. Clin Transl Med. 2013; 2(1):6.

2. Fernandez-Viña MA. HLA factors in transplantation for nonmalignant hematologic disorders. Blood. 2012; 120(14): 2781-2. experience on this panel for using of these cells as tools in different biologic works (31).

In the study of Degli-Esposti, 100 EBVtransformed cells and more than 150 cell lines were typed and were introduced as a cell panel with defined HLA alleles (32). Kim developed a Korean HLA reference panel by HLA typing of more than 400 individuals in East Asians, including Koreans (33).

In the previous studies, various cell lines, virus-transformed cells or blood cells derived from healthy individuals were used to develop reference panels. But using of these panels was accompanied with difficulties such as not being national, not being easily accessible and being expensive.

\section{Conclusion}

HLA-typed MSCs could be prepared from each available MSC-containing tissue for example umbilical cord and used as reference cells in DNA-based HLA-typing techniques. These cells could be kept in liquid nitrogen and cultured periodically to obtain enough DNA as the base material in molecular studies.

\section{Acknowledgments}

This study was the result of a thesis financially supported by Blood Transfusion Research Center, High Institute for Research and Education in Transfusion Medicine, Iranian Blood Transfusion Organization, Tehran.

3. Hurley CK, Wade JA, Oudshoorn M, Middleton D, Kukuruga D, Navarrete $\mathrm{C}$, et al. A special report: histocompatibility testing guidelines for hematopoietic stem cell transplantation using volunteer donors. Tissue Antigens. 1999; 53: 394-406. 
4. Erlich HA, Opelz G, Hansen J. HLA DNA typing and transplantation. Immunity. 2001; 14(4): 347-56.

5. Koo HH, Ahn HS. Umbilical cord blood transplantation. Korean J Pediatr. 2012; 55(7): 219-23.

6. Horan J, Wang $T$, Haagenson $M$, Spellman SR, Dehn J, Eapen M, et al. Evaluation of HLA matching in unrelated hematopoietic stem cell transplantation for nonmalignant disorders. Blood. 2012; 120(14): 291824.

7. Middelton D. HLA Typing from Serology to Sequencing Era. Iran J Allergy Asthma Immunol. 2005; 4(2): 53-66.

8. Borelli SD, Souza D, Freitas KFF, Botini FF, de Melo FC, Bedendo J. Comparative study between serological and PCR-SSP methods to determine class II HLA molecules. Maringá. 2004; 26(2): 337-340.

9. Mishra MN, Mani H, Narula AS, Saxena VK. HLA Typing - A Comparison of Serology and DNA Techniques. Int J Hum Genet. 2004; 4(2): 151-153.

10. Adib M, Yaran M, Rezaie A, Solgi G. HLA-DR Typing by Polymerase Chain Reaction with Sequence- Specific Primers Compared to Serological typing. J Res Med Sci. 2004; 6: 255259.

11. Song S, Han M, Zhang H, Wang Y, Jiang H. Full screening and accurate subtyping of HLA-A*02 alleles through group-specific amplification and monoallelic sequencing. Cell Mol Immunol. 2013; 10(6): 490-6.

12. Lin JS, Tzeng CH, Huang DF, Lyou JY, Chen YJ, Hu HY, et al. HLA-DR typing by polymerase chain reaction amplification with sequence-specific primers in paternity disputes. J Chin Med Assoc. 2003; 66(2): 77-83.

13. Hammond E, Almeida CA, Mamotte C, Nolan D, Phillips E, Schollaardt TA, et al. External quality assessment of HLA$\mathrm{B} * 5701$ reporting: an international multicentre survey. Antivir Ther. 2007; 12(7): 1027-32.

14. Safa M, Forouzandeh M, Pourfathollah A, Gill P, Rasaee M, Yari F, et al. High Resolution Allotyping of Four Alleles of HLA-DRB $1 * 01$ Group in Iranians Using Revers-SSOPH Assay in Comparison with DNA Sequencing and PCR-SSP. J Biol Sci. 2008; 8(2): 392397.

15. Jia X, Han B, Onengut-Gumuscu S, Chen WM, Concannon PJ, Rich SS, et al. Imputing amino acid polymorphisms in human leukocyte antigens. PLoS One. 2013; 8(6): e64683.

16. Petersdorf EW, Malkki M, Hsu K, Bardy P, Cesbron A, Dickinson A, et al. 16th IHIW: international histocompatibility working group in hematopoietic cell transplantation. Int $\mathbf{J}$ Immunogenet. 2013; 40(1): 2-10.

17. Baksh D, Song L, Tuan RS. Adult mesenchymal stem cells: characterization, differentiation, and application in cell and gene therapy. $\mathrm{J}$ Cell Mol Med. 2004; 8(3): 301-16.

18. Couto PS. Isolation of human umbilical cord mesenchymal stem/stromal cells from a stem cell bank perspective: an integrated overview. IJPCBS. 2014; 4(2): 391-410.

19. Augello A, Kurth TB, De Bari C. Mesenchymal stem cells: a perspective from in vitro cultures to in vivo migration and niches. Eur Cell Mater. 2010; 20: 121-33.

20. Nagamura-Inoue T, He H. Umbilical cord-derived mesenchymal stem cells: Their advantages and potential clinical utility. World J Stem Cells. 2014; 6(2): 195-202.

21. Eslaminejad MB, Vahabi S, Shariati M, Nazarian H. In vitro Growth and Characterization of Stem Cells from Human Dental Pulp of Deciduous Versus Permanent Teeth. J Dent (Tehran). 2010; 7(4):185-95.

22. Li DR, Cai JH. Methods of isolation, expansion, differentiating induction and preservation of human umbilical cord 
mesenchymal stem cells. Chin Med J (Engl). 2012; 125(24): 4504-10.

23. Madrigal M, Rao KS, Riordan NH. A review of therapeutic effects of mesenchymal stem cell secretions and induction of secretory modification by different culture methods. J Transl Med. 2014; 12: 260.

24. Baghaban Eslaminejad M, Malakooty Poor E. Mesenchymal stem cells as a potent cell source for articular cartilage regeneration. World J Stem Cells. 2014; 6(3):344-54.

25. Hass R, Kasper C, Böhm S, Jacobs R. Different populations and sources of human mesenchymal stem cells (MSC): A comparison of adult and neonatal tissue-derived MSC. Cell Commun Signal. 2011; 9: 12.

26. Emadedin M, Aghdami N, Taghiyar L, Fazeli R, Moghadasali R, Jahangir S, et al. Intra-articular injection of autologous mesenchymal stem cells in six patients with knee osteoarthritis. Arch Iran Med. 2012; 15(7):422-8.

27. Hinrichs J, Figueiredo C, Hirv K, Mytilineos J, Blasczyk R, Horn PA, et al. Discrimination of HLA null and low expression alleles by cytokine-induced secretion of recombinant soluble HLA. Mol Immunol. 2009; 46(7): 1451-7.

28. Reinhold WC, Varma S, Sousa F, Sunshine M, Abaan OD, Davis SR, et al. NCI-60 whole exome sequencing and pharmacological CellMiner analyses. PLoS One. 2014; 9(7): e101670.

29. Wittig M, Anmarkrud JA, Kässens JC, Koch S, Forster M, Ellinghaus E, et al. Development of a high-resolution NGS-based HLA-typing and analysis pipeline. Nucleic Acids Res. 2015; 43(11): e70.

30. Hemmatpour SK, Evans PR, McQuilkin S, Sage DA, Howell WM. HLA class I A and B typing in the clinical laboratory using DNA-based techniques. Transpl Int. 1996; 9 Suppl 1: S356-63.

31. Adams S, Robbins FM, Chen D, Wagage D, Holbeck SL, Morse HC 3rd, et al. HLA class I and II genotype of the NCI-60 cell lines. J Transl Med. 2005; 3(1): 11 .

32. Degli-Esposti MA, Griffiths MS, Daly LN, Witt CS, Simons M, Carcassi C, et al. Characterization of $4 \mathrm{AOHW}$ cell line panel including new data for the 10IHW panel. Hum Immunol. 1993; 38(1): 3-16.

33. Kim K, Bang SY, Lee HS, Bae SC. Construction and application of a Korean reference panel for imputing classical alleles and amino acids of human leukocyte antigen genes. PLoS One. 2014; 9(11): e112546. 